\title{
PHYSICO-MECHANICAL AND ELECTRICAL PROPERTIES OF ALUMINUM-BASED COMPOSITE MATERIALS WITH CARBON NANOPARTICLES
}

\author{
S. Vorozhtsov ${ }^{1,2}$, D. Eskin ${ }^{3}$, A. Vorozhtsov ${ }^{1}$, S. Kulkov ${ }^{1,2}$ \\ ${ }^{1}$ National Research Tomsk State University, Tomsk \\ ${ }^{2}$ Institute of Strength Physics and Materials Science SB RAS, Tomsk \\ ${ }^{3}$ Brunel Centre for Advanced Solidification Technology, Brunel University; Kingston Lane, \\ Uxbridge, UB8 3PH, UK
}

Keywords: Composite material, Aluminum alloy, Nanodiamonds, X-ray, Mechanical properties

\begin{abstract}
Nanocomposite materials with the matrix of an A356 alloy reinforced with 0.2 and $1 \mathrm{wt} \%$ of high-elastic nanodiamonds were produced by ultrasonic dispersion of nanoparticles in the melt followed by casting in a metallic mold. The structure as well as the physical and mechanical properties of the cast samples were examined using optical and scanning electron microscopy, hardness and tensile testing. It is shown that the hardness, Young's modulus and electrical resistivity increase with introduction of nanodiamond particles.
\end{abstract}

\section{Introduction}

Al based alloys and composites reinforced with non-metallic particles are nowadays of great interest in various fields of technology due to their high specific strength, hardness, durability etc. Casting is the most versatile method of production of such composite materials. A commercial A356 alloy (Al-Si-Mg system) is one of the possible matrix variants. The A356 cast alloy due to good castability, welding characteristics, corrosion resistance and perfect mechanical properties has a wide range of applications including automotive and aerospace industry [1]. Micro- and nano-sized particles of oxides, carbides, borides etc. can be used as reinforcing particles. A relevant method of such reinforcement consists in embedding of high-modulus detonation nanodiamonds [2,3] with nanocrystalline structure into the soft $\mathrm{Al}$ matrix. Unlike oxides, carbides and others which may change their structure due to interaction with the matrix, such particles remain stable at high temperatures (up to $1000^{\circ} \mathrm{C}$ according to [3]) and can stabilize mechanical and physical properties of alloys in a wide range of temperatures.

It is known that direct embedding of refractory particles (especially nanosized ones) into liquid metal is not possible due to the fact that they are prone to agglomeration and flotation caused by their low wettability by liquid metal. This problem can be solved using the impact of external fields on liquid metals which leads to de-agglomeration of nanoparticles and their homogeneous distribution in the melt volume and ingot structure as a result. Ultrasonic treatment is one of the most efficient ways of melt treatment leading to alloy grain size reduction and homogeneous distribution of reinforcing particles in its structure [4, 5]. Besides, ultrasonic treatment intensifies degassing process, provides additional mixing, prevents coring and concentration of non-metal inclusions on grain boundaries, which has a positive impact of the formation of uniform metal structure in the process of solidification [6].
The objective of this work is to study physical and mechanical properties of composites based on an A356 alloy, containing detonation nanodiamonds.

\section{Materials and methods}

A commercial A356 alloy (Al-Si-Mg system) and a batch mixture containing crystalline and amorphous phases of carbon and detonation nanodiamonds [7] were used as materials for the study.

The A356 alloy was melted in a graphite crucible with a total melt volume of $1 \mathrm{~kg}$. Ultrasonic degassing was performed at the melt temperature of $720^{\circ} \mathrm{C}$ for 1 minute. Then, reinforcing particles were introduced simultaneously with ultrasonic treatment. The latter was performed using a $5-\mathrm{kW}$ water-cooled magnetostrictive transducer with a working frequency of $17.5 \mathrm{kHz}$. Conical radiator with a working null-peak amplitude of about $30 \mu \mathrm{m}$ was made of niobium. In order to improve wettability, detonation nanodiamonds were premixed with ultrafine $\mathrm{Al}$ powder and then packed in aluminum foil. A rod-shaped container with powders was heated in the furnace up to $200^{\circ} \mathrm{C}$ and then introduced into the cavitation zone in the melt. The melt was treated with ultrasound for 10 minutes after introduction of the particles. Then the obtained mixture was poured at $700^{\circ} \mathrm{C}$ into a metallic mold with the cavity size of $\varnothing 30 \times 110 \mathrm{~mm}$. The nominal nanoparticles content in the alloy was 0.2 and $1 \mathrm{wt} \%$. Reference samples were produced using the similar processing parameters but without particle introduction.

The study a phase composition and structural parameters of detonation nanodiamonds and $\mathrm{Al}$ composites was performed using an X-ray diffractometer with $\mathrm{Cu} K_{\alpha}$ radiation. Calculation of coherent scattering domain (CSD) and microdistortion of the crystal lattice $\left\langle\varepsilon^{2}\right\rangle^{1 / 2}$ was performed using Williamson-Hall method where all broadenings on X-ray diffraction profile are used for calculation. Powder morphology was studied using Philips CM 12 transmission electron microscope (TEM).

Mechanical behavior of specimens of $\mathrm{Al}$ alloys (quasi-static tension) was studied using Instron 3369 testing machine. Guaranteed frame stiffness for this machine corresponds to 250 $\mathrm{kN}$ load, load accuracy of $0.5 \%$ of indicated load. Ultimate load during specimen testing procedures did not exceed $1.5 \mathrm{kN}$. Movable grip traveling speed comprised $0.01 \mathrm{~mm} / \mathrm{s}$, which corresponds to a strain rate of $2 \times 10^{-4} \mathrm{~s}^{-1}$.

The structure of obtained materials was studied using scanning electron microscopy (Philips SEM 515) and optical microscopy (Neophot 21).

Microhardness and Young's modulus were measured using Nano Indenter G200/XP tester with a load of $250 \mathrm{~g}$. Hardness was 
measured using Brinell hardness tester with a load of $1 \mathrm{~kg} .10$ hardness measurements were performed for various surface areas of the samples.

The measurement of electric resistivity was made with a fourpoint electric circuit with simultaneous heating of samples to determine the temperature coefficient of resistivity.

\section{Results and discussion}

TEM image of a powder containing detonation nanodiamonds is shown on Fig. 1 a. It can be seen that the powder has a finecrystalline morphology. However, according to SEM data, it contains particle agglomerates with the sizes of about $10 \mu \mathrm{m}$. The analysis of electron microdiffraction pattern for the powder (Fig. 1 b) indicates that diffraction lines correspond to cubic diamond phase. The average size of diamond microclusters according to small-angle X-ray scattering data is $4 \mathrm{~nm}$ [2]. In accordance with $\mathrm{X}$-ray phase analysis the powder contains an X-ray amorphous phase $(40 \pm 5 \%)$ and a diamond phase $(45 \pm 5 \%)$, there are also traces of the crystalline carbon. The average size of coherent scattering domain for nanopowder according to X-ray diffraction analysis is $4 \mathrm{~nm}$, whereas the microdistorsion of the crystal lattice is estimated as $1.7 \times 10^{-2}$

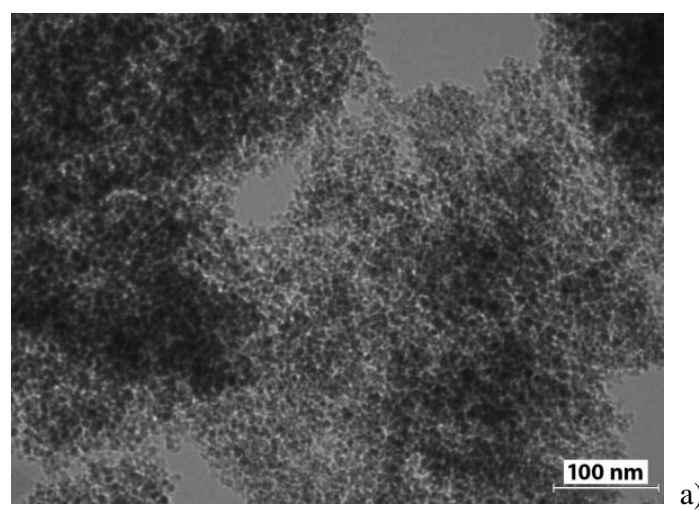

a)

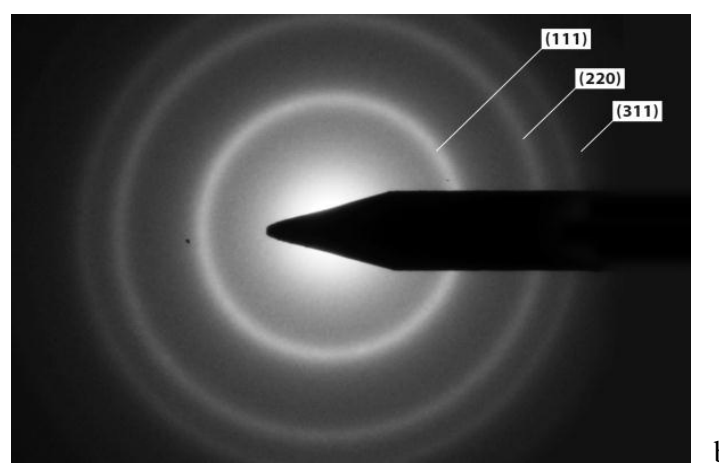

b)

Figure 1. TEM image of powder containing detonation nanodiamonds (a) and corresponding electron microdiffraction pattern (b).

Microstructure of alloys with different nanoparticle content is shown on Fig.2. The porosity of materials can be seen. The porosity volume of the base alloy comprises less than $2 \%$ as the pores are small. Larger pores are formed along with fine porosity in alloys containing nanoparticles, and the total pore volume increases with the increase of nanoparticle content. Large pore are probably formed around agglomerates of nanoparticles.

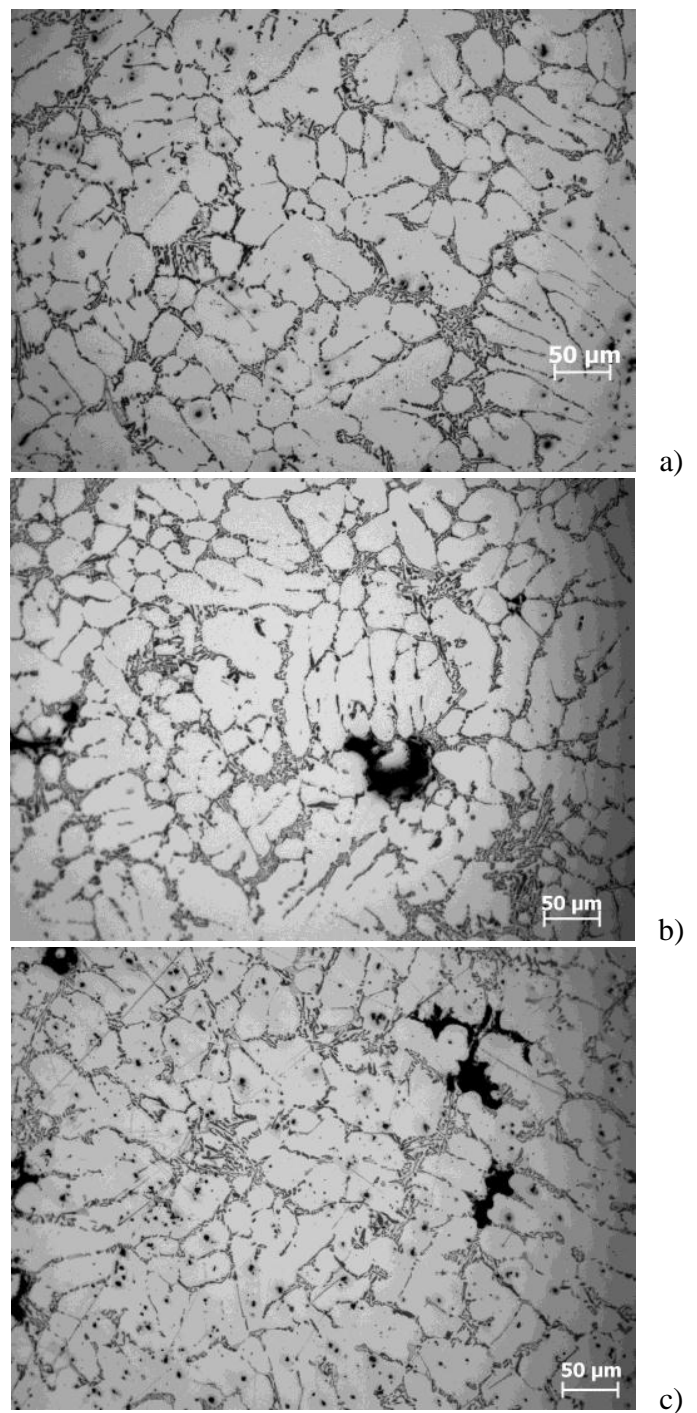

Figure 2. Microstructure of the reference A356alloy (a); and composites A356+0.2\% C (b); A356+1\% C (c).

Average grain size calculation (Fig. 3) indicates that alloys containing $0.2 \%$ of nanoparticles has the average grain size reduced from 210 to $170 \mu \mathrm{m}$, whereas for the alloy with an addition of $1 \%$ of $\mathrm{C}$ the average grain size is up to $220 \mu \mathrm{m}$, i.e. it is almost the same as for reference alloy without nanoparticles.

$\mathrm{X}$-ray diffraction analysis results are given in Table 1 . As it can be seen, the size of CSD of the Al-based matrix with nanoparticles embedded reduces. Particularly, the CSD size of the reference alloy (without nanoparticles) measured $140 \mathrm{~nm}$, whereas as for the alloy with $1 \% \mathrm{C}$ the size of CSD reduces to $80 \mathrm{~nm}$. Moreover, microdistortion of the crystal lattice also reduces, and alloys containing $1 \%$ of nanoparticles demonstrate almost $50 \%$ reduction of lattice microdistortion. Crystal lattice parameter for $\mathrm{Al}$ in all cases is higher than the tabulated value $(0.40496 \mathrm{~nm}[8])$. The increased crystal lattice parameter can be attributed to a higher degree of microdistortions due to elements dissolved in $\mathrm{Al}$ as well as due to embedding of nanoparticles into the matrix. In case of material containing $1 \%$ of carbon the reduction of microdistortion goes along with the reduction of lattice parameter towards the tabulated value. 


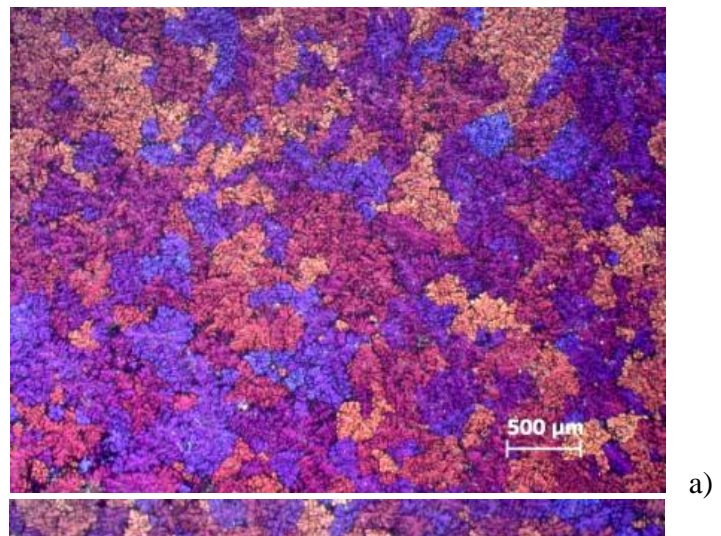

a)

b)

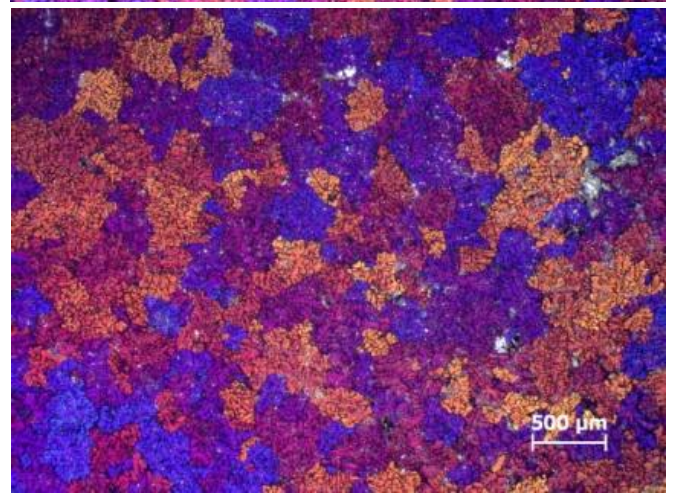

c)

Figure 3. Microstructure of the reference alloy A356 (a); $\mathrm{A} 356+0.2 \% \mathrm{C}(\mathrm{b}) ; \mathrm{A} 356+1 \% \mathrm{C}$ (c).

Tensile stress-strain diagrams for alloys with different amounts of nanoparticles are shown on Fig. 4. It was found that embedding of $0.2 \%$ of nanoparticles leads to significant improvement of mechanical properties - increase of ultimate tensile strength, yield strength, Young's modulus and ductility, which corresponds to data on lattice distortion in Table 1.

Table 1. X-ray diffraction analysis results

\begin{tabular}{|l|c|c|c|}
\hline Material & $\begin{array}{l}\text { CSD Al, } \\
\mathrm{nm}\end{array}$ & $\left\langle\varepsilon^{2}\right\rangle^{1 / 2}$ & $\begin{array}{l}\text { Al lattice } \\
\text { parameter } a, \\
\text { nm }\end{array}$ \\
\hline A356 & 140 & $5 \times 10^{-4}$ & 0.4059 \\
A356+0.2\%C & 90 & $4.7 \times 10^{-4}$ & 0.40629 \\
A356+1\%C & 80 & $2.8 \times 10^{-4}$ & 0.40519 \\
\hline
\end{tabular}

It is likely that this improvement of mechanical properties of alloys with $0.2 \%$ of carbon nanoparticles is determined by Orowan effects [9].

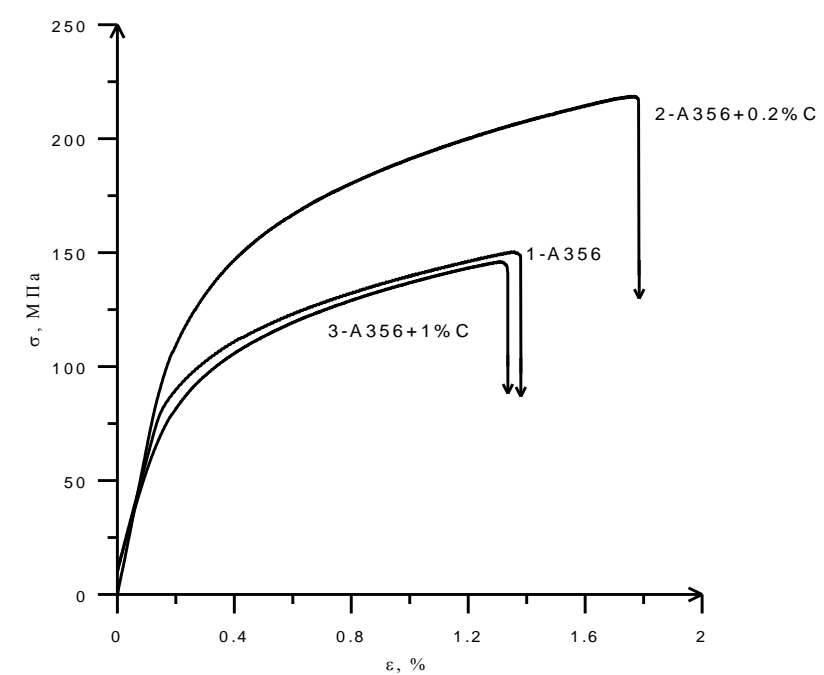

Figure 4. Stress-strain diagrams of A356 reference alloys and composites with different amounts of detonation nanodiamonds.

However, embedding of a greater amount of nanoparticles (up to $1 \%$ ) leads to the increase of porosity and formation of agglomerates which impairs mechanical properties of the alloy. Fracture surfaces of the studied materials are shown on Fig. 5. As it can be seen there are shrinkage pores of $100-300 \mu \mathrm{m}$ in diameter on the fracture surfaces of the specimens (white contour lines). These pores were formed in the process of solidification. Although the fracture mode does not change, the increasing pore volume leads to earlier fracture of the composite with the high particle content.

Mechanical properties of the reference alloy and the composites are given in Table 2. It can be seen that materials' hardness (measured by two different methods) increases. At the same time there is an increase of elasticity modulus, calculated using load curves as well as Young's modulus determined using indentation. Such change of modulus and strength goes well along with the reduction of average grain size and dendritic arm spacing from 37 $\mu \mathrm{m}$ for initial alloy to $27 \mu \mathrm{m}$ for alloys containing particles (marked with arrows in Fig. 5).

Table 2. Mechanical properties of the reference alloy and composites

\begin{tabular}{|l|c|c|c|c|}
\hline Material & $\begin{array}{l}\text { Micro } \\
\text { hardness } \\
\mu \mathrm{H}, \mathrm{MPa}\end{array}$ & $\begin{array}{l}\text { Brinell } \\
\text { hardness, } \\
\mathrm{HB}\end{array}$ & $\begin{array}{l}\text { Young's } \\
\text { modulus, } \\
\mathrm{E}, \mathrm{GPa} \\
\text { (indenta- } \\
\text { tion) }\end{array}$ & $\begin{array}{l}\mathrm{E}_{\mathrm{ef}}, \\
\mathrm{GPa} \\
\text { (load } \\
\text { curves) }\end{array}$ \\
\hline A356 & 870 & 40 & 40 & 48 \\
A356+0.2\%C & 1380 & 55 & 86 & 65 \\
A356+1\%C & 1360 & 60 & 85 & 44 \\
\hline
\end{tabular}




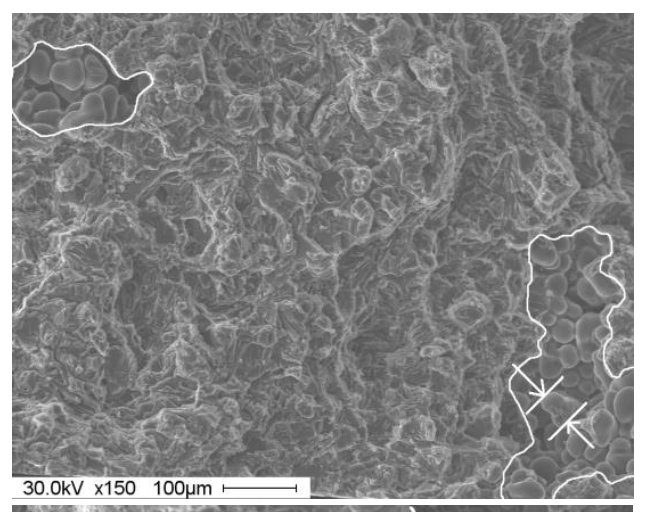

a)
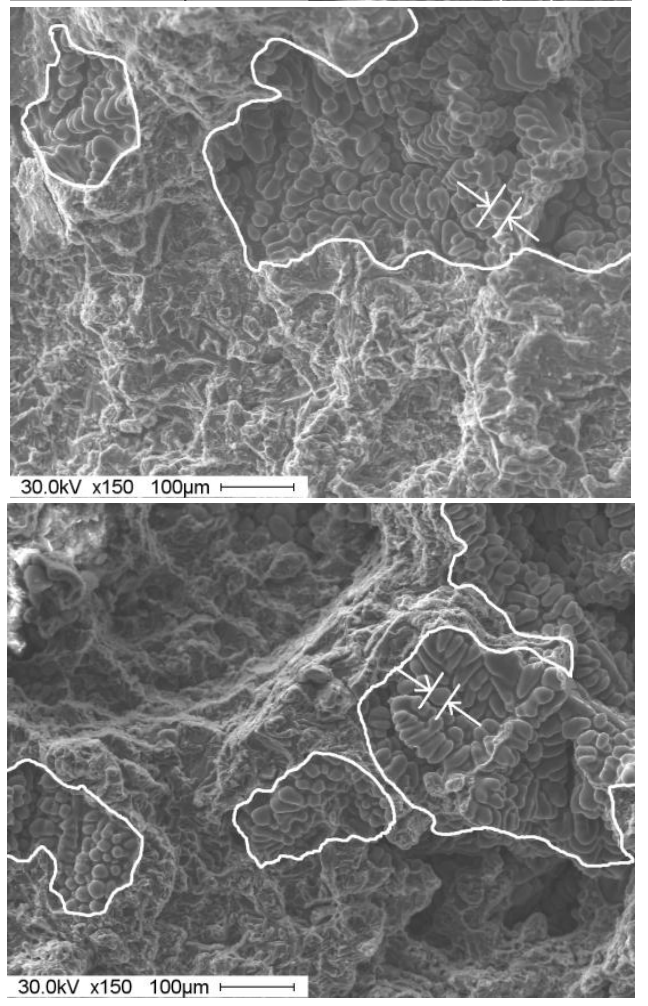

b)

c)

Figure 5. Fracture surface of the reference alloy (a) and composites: (b) A356+0.2\% C; (c) A356+1\% C.

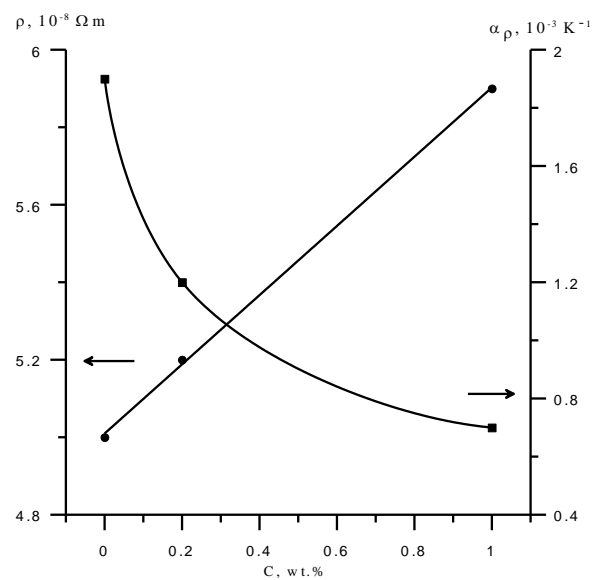

Figure 6. Dependence of electrical resistivity and temperature coefficient on the concentration of nanodiamonds.
Figure 6 gives the dependences of electrical resistivity $(\rho)$ and temperature coefficient $\left(\alpha_{\rho}\right)$ on the concentration of nanodiamonds in the A356 alloy. The introduction of nanoparticles into the alloy increases the resistivity from $5 \times 10^{-8}$ up to $5.9 \times 10^{-8} \Omega \mathrm{m}$, and that data was obtained with taking into account the changes in porosity within the samples. In addition, temperature coefficient of resistivity decreases significantly from $1.9 \times 10^{-3}$ to $0.7 \times 10^{-3} \mathrm{~K}^{-1}$. Such changes of $\rho$ и $\alpha_{\rho}$, are evidently due to the influence of additional interfaces with high resistivity formed by nanoparticles.

\section{Conclusions}

It is shown that the size of coherent scattering domains for $\mathrm{Al}$ phase in the A356-based composites with detonation nanodiamonds decreases from 140 to $80 \mathrm{~nm}$.

It is found that embedding of $0.2 \%$ of detonation nanodiamonds into the alloy leads to significant improvement of mechanical properties of materials - increase of ultimate tensile strength, yield strength, Young's modulus and hardness.

It is shown that introduction of nanoparticles into alloy leads to increase of resistivity, in addition, temperature coefficient of resistivity decreases.

The increase of porosity after embedding of particles indicates that the process of production of composites requires further optimization.

\section{Acknowledgment}

The authors wish to acknowledge financial support from the ExoMet Project, which is co-funded by the European Commission in the 7th Framework Program (contract FP7-NMP3-LA-2012280421)

\section{References}

1. Q.G. Wang. Metall. Mater. Trans. A, 2003, vol. 34A, pp. 28872899.

2. G.V. Sakovich, V.F. Komarov, E.A. Petrov. Sverkhtverd. Mater., 2002, no. 3, pp. 3-18.

3. A.A. Gromov, S.A. Vorozhtsov, V.F. Komarov, G.V. Sakovich, Yu. I. Pautova, M. Offermann. Mater. Lett., 2013, vol. 91, pp. 198-201.

4. G.I. Eskin. Ultrason. Sonochem., 1994, vol. 1, pp. 59-63.

5. H. Choi, M. Jones, H. Konishi, X. Li. Metall. Mater. Trans. A, 2012, vol. 43A, pp 738-746.

6. G.I. Eskin. Ultrasonic Treatment of Light Alloy Melts. Amsterdam: Gordon and Breach OPA, 1998. 334 p.

7. S.A. Vorozhtsov, S.P. Buyakova, S.N. Kulkov. Izvestiya Vyssh. Uchebn. Zaved. Poroshk Metall. Mnogofunktsion. Pokryt., 2011, no. 1, pp. 52-57.

8. ASM Alloy Phase Diagrams Center, P. Villars, H. Okamoto and K. Cenzual, eds; Material Park (OH): ASM International, 2007.

9. I.I. Novikov, K.M. Rozin. Crystallography and Crystal Lattice Defects. Moscow: Metallurgiya. 1990. 338 p./ 